\title{
Effective Review of Prerequsites: Using Videos to Flip the Reviewing Process in a Senior Technical Course
}

\section{Dr. Qi Dunsworth, Penn State Behrend}

Qi Dunsworth is the Director of Center for Teaching Initiatives at Penn State Erie, the Behrend College. She received her MA in Communication Studies from Edinboro University of Pennsylvania, and Ph.D. in Educational Technology from Arizona State University. At Behrend she supports faculty in classroom teaching, research, and collaboration. She has developed a series of faculty teaching workshops and is the recipient of several grants for course revision, educational research, and professional development.

\section{Dr. Yi "Elisa" Wu, Penn State Behrend}

Yi Wu is currently an Associate Professor in the Department of Mechanical Engineering, Pennsylvania State University, Erie, the Behrend College. She received Ph.D. degrees in mechanical and aerospace engineering from the University of Virginia. Her current research interests include modeling of complex physiological systems, drug design, dynamics and control, and engineering education. 


\title{
Effective review of prerequisites: using videos to flip the reviewing process in a senior technical course
}

\begin{abstract}
Senior level courses in engineering curriculum typically require multiple prerequisites from the years earlier. This paper discusses how we solve the challenge in teaching a biomechanics course offered to senior Mechanical Engineering students. The course is designed to teach students how to apply mechanical engineering knowledge in the biomedical field. It covers a wide range of topics and is built on five prerequisite courses. Students take these courses from sophomore through senior years but not necessarily following the same technical sequence. Given this situation, it is critical to make sure students have mastered the foundational knowledge and skills before transferring them to the biomedical context.

Traditionally, in each unit of the course the instructor would need about two to three weeks just to review the relevant prerequisite knowledge. This means there is less time left to discuss class examples or advanced topics in bioengineering. To make the review process more efficient, in fall 2016, the instructor adopted a "flipped review" approach by replacing classroom review with a series of review video and quiz combos outside of class. Each combo consisted of one video focused on one technical area followed by an online quiz. They were assigned to students across the semester to support unit-specific topics where the technical knowledge would be needed. All video and quiz combos were due before the class meeting time.

Based on positive student feedback, the review series was revised when the course was offered again in spring 2018. This paper will discuss the effectiveness of "flipped review" by using review videos to reactivate student prior knowledge. Student feedback used in this paper came primarily from spring 2018. The must-have features suggested by students, and instructor reflection on how to make the review videos effective, will also be shared.
\end{abstract}

\section{Introduction}

\section{A. An instructional challenge}

ME 491, Bioengineering Applications of Mechanical Engineering, is a biomechanics course offered as an elective for senior mechanical engineering students in the School of Engineering at Penn State Erie, the Behrend College. Students meet twice a week at 75 minutes each for 15 weeks. As the only course connecting ME to the biomedical field, it focuses on the application of mechanical engineering knowledge and skills in the context of life science. A range of topics in biomechanics, such as motion biomechanics, physiological fluid mechanics, physiological modeling, rehabilitation engineering, etc., are discussed in this course. 
Like many senior electives, the applied nature of this course demands students to have a solid foundation before they can proceed. In ME 491, approximately $75 \%$ of the foundational knowledge and skills come from the prerequisites: two in solids mechanics, one in fluid/thermal science, one in electrical circuits, and one in system dynamics. If the required courses of these five prerequisites are also taken into account, then eight engineering courses are the building blocks for ME 491: statics, dynamics, strength of materials, intermediate strength of materials, thermal system, fluid mechanics, electrical circuits, and system dynamics. Students take these courses from sophomore through junior/senior years but not necessarily following the same technical sequence. Given this situation, it is critical to reactivate the prerequisite knowledge first so that students are ready to transfer ME skills to the biomedical context.

Traditionally, for each unit that requires extensive prerequisite knowledge, the instructor would spend lecture time going over key concepts taught in previous courses. The class will then learn about relevant human biology. Only after students have adequate background in both ME and biology, can the class move on to introducing biomedical problems, and only then will the students be able to practice applying ME skills to the biomedical field through homework assignments.

Although the in-class review approach does improve student readiness for the discussion of advanced topics, it carries a hefty cost. First, a total of two to three weeks of the semester are allocated for reviewing prior knowledge alone. Second, the pace of reviewing is maxed at roughly one foundational course per class meeting. Third, the time to discuss the example biomechanics problem is compressed to the minimum. As a result, active learning activities are unaffordable given the time constraint, and the new content can only be covered through oneway, straight lectures. Most importantly, there is little time left for advanced topics critical to the bioengineering field. For example, dynamics of rigid body in three dimensions - translation plus rotation - is an advanced topic that applies to all human motion in real life, yet the instructor has never had the chance to discuss it. In order to reposition ME 491 as a senior level course for advanced topics, the prerequisite review process must be done more efficiently.

\section{B. The flipped classroom model}

In the past several years, flipped classroom has gained much popularity from K-12 to higher education. This instructional model is characterized by having students learn course content prior to class meetings [4], so that class time can be used for interactive activities that are more meaningful to student learning. By reversing the roles teachers and students play in a traditional learning environment, the classroom is then "flipped" or "inverted" $[2,6]$. As summarized by Schmidt and Ralph [15], the "I do", "We do", "You do" teaching approach has become "You do", "We do", "I do".

A flipped classroom, when designed and implemented well, can provide a range of benefits. For instructors, having students learn outside of the class gives them more time to cover additional selected topics [6]. Instructors will also have the freedom to use class time for highly interactive activities [2] through team-based learning, problem-based learning, or hands-on projects etc.. They will also likely to give more personal attention and guidance to the students. In addition, once the preparation of assigned learning tasks is complete, content delivery will require minimal efforts when the class is offered again [2]. For students, a flipped class places the control in the hands of students. For example, students can pause and replay an instructional video as many 
times as needed. When they come to class prepared, they are more likely to be engaged in discussions, group work, or team projects. When students get to apply what they just learned, learning becomes fun and rewarding [6].

Nonetheless, the path to a successfully flipped class is not without pitfalls. Instructors need to carefully consider what type of content and how much is appropriate to be assigned outside of class. Previous studies have shown that pre-class activities should be used to support lower levels of cognitive work [3] or the "first exposure" of content knowledge [5]. One of the big challenges is to ensure students complete the assigned learning outside of class and come to class prepared. If they don't, the in-class activities will unlikely go well. As suggested by the best practices in the literature $[3,4,6]$, educators need to consider how course material will be delivered outside of class, in what format, and most importantly, how to assess student learning.

\section{The flipped review approach}

Given the benefits of flipped classroom and the necessity to help students recall prerequisite knowledge, ME 491 is a good candidate for adopting a modified version of flipped instruction which we call the "flipped review" approach. Although there are five prerequisite courses to be reviewed, the reviews can be accomplished by a series of five videos and corresponding mini assessments. The content designed to be covered by the original ME 491 course does not need to be flipped. Overall, the amount of review to be completed takes only a modest portion of the course, which makes the creation of review assignments manageable. Because of that, we dub our instructional approach the "flipped review" instead of a "flipped class." In a flipped class, class meeting time is devoted to the same topics students learned on their own but are investigated with more depth. In ME 491, class time is not used to reinforce the prerequisite knowledge but to lay out the human biology background in order to solve the upcoming biomedical problems students have not seen before.

With this rationale, in fall 2016, the instructor replaced all in-class reviews with five video/quiz review assignments. They were distributed throughout the course to best support unit-specific topics. Each video was bundled with a graded quiz. Students must complete the video/quiz review assignment before the first class of a learning unit. Students were surveyed throughout the course to provide feedback on video features and its helpfulness to learning. With the "flipped" approach, the instructor was able to allocate more time for in-depth application problems or for advanced topics.

Based on positive student feedback from 2016, the review videos were revised with added interactive features for class in spring 2018. In this paper, we will present our material design rationale and the results from the spring 2018 class. A list of must-have features for review videos and instructor reflection on course and video production will also be shared.

\section{Course Set-Up and Course Material Design}

\section{A. Course set-up}

Like other engineering courses in the curriculum, student academic performance in ME 491 is assessed through a variety of assignments. The weight of each category of assignments are listed in Table 1. Five assignments were designed to help students review prerequisite knowledge and 
skills. They are distributed across different learning units with a total weight of $7 \%$ of the course grade. Each review assignment includes a video followed by an online quiz, both due before the class when the knowledge and skills are needed in order to solve a problem in class. Students can take the online quiz up to two times, and the average score will be recorded in the gradebook. The problem given in class is not graded.

The idea of attaching a graded quiz to the review video is supported by our experience as well as the literature of teaching a flipped class [1]. Simply asking students to prepare for class would not be enough. To make sure students would invest efforts in reviewing and understanding the videos, the content of the videos must be directly related to a grade-bearing assignment $[8,12]$.

Table 1. Course assignments and their weights in relation to course grade.

\begin{tabular}{|l|l|}
\hline Categories of learning assessments & Weight in course grade \\
\hline${ }^{\circledR}$ Review assignments (review videos/quizzes) & $7 \%$ \\
\hline${ }^{\circledR}$ Homework problems & $7 \%$ \\
\hline${ }^{\circledR}$ Comprehensive projects & $72 \%$ \\
\hline${ }^{\oplus}$ Application presentation & $6 \%$ \\
\hline Surveys & $5 \%$ \\
\hline Attendance/summary & $3 \%$ \\
\hline
\end{tabular}

On a typical due day of a review assignment, the first twenty minutes were used for student presentation $^{\oplus}$ on biomedical applications, then the instructor will give a 20-30 minutes interactive lecture on human physiology. After that, a biomechanics problem will be given to the students. Students will first work on the problem independently for about 20 mins, then the instructor will lead students to work through the problem until class ends.

The coverage of the course is chunked in several learning units. To start each unit, the review video/quiz ${ }^{\mathbb{D}}$ is assigned first, followed by the class meeting, then one or two sets of homework problems $^{(2)}$ after class, and finally a comprehensive project ${ }^{\circledR}$. The content of review video/quiz are completely from the prerequisite courses, and they are strictly presented in the engineering context. The homework problems and projects, however, require students to transfer engineering skills to the biomedical field, and may include newly taught topics.

The instructional sequence of each learning unit is designed for students to start with easier material as they need to reactivate, or in some cases, relearn the prerequisite knowledge. As students follow the sequence, they will encounter more challenging problems that demand an indepth understanding of the technical area. From the course design perspective, the review videos/quizzes are the foundation of subsequent homework problems and projects. 


\section{B. Features of the review videos}

Five videos were created to help students review the prerequisite knowledge and skills. All videos were contained between 9 to 11 minutes in length as shorter videos have a better chance to be viewed through $[8,10,12]$. Each video provides a summary of key concepts in one of the five technical areas: statics, dynamics, strength of materials, one-dimensional pipe flow, and system dynamics.

Over the course of creating review videos, we have built and kept a list of features. The rationale is provided for each of them below.

\section{1) Clarifying the purpose of the video}

Since most instructional videos online intend to teach the audience something new, the viewers are used to expecting detailed information such as step-by-step explanations. But for videos intend to review prerequisite courses, it's impossible to pack an entire course in just 10 minutes. To avoid the misconception that review videos can be used as a substitute for teaching an entire course, the purpose of the review video has to be explicitly stated on the opening slide, as shown in Figure 1.

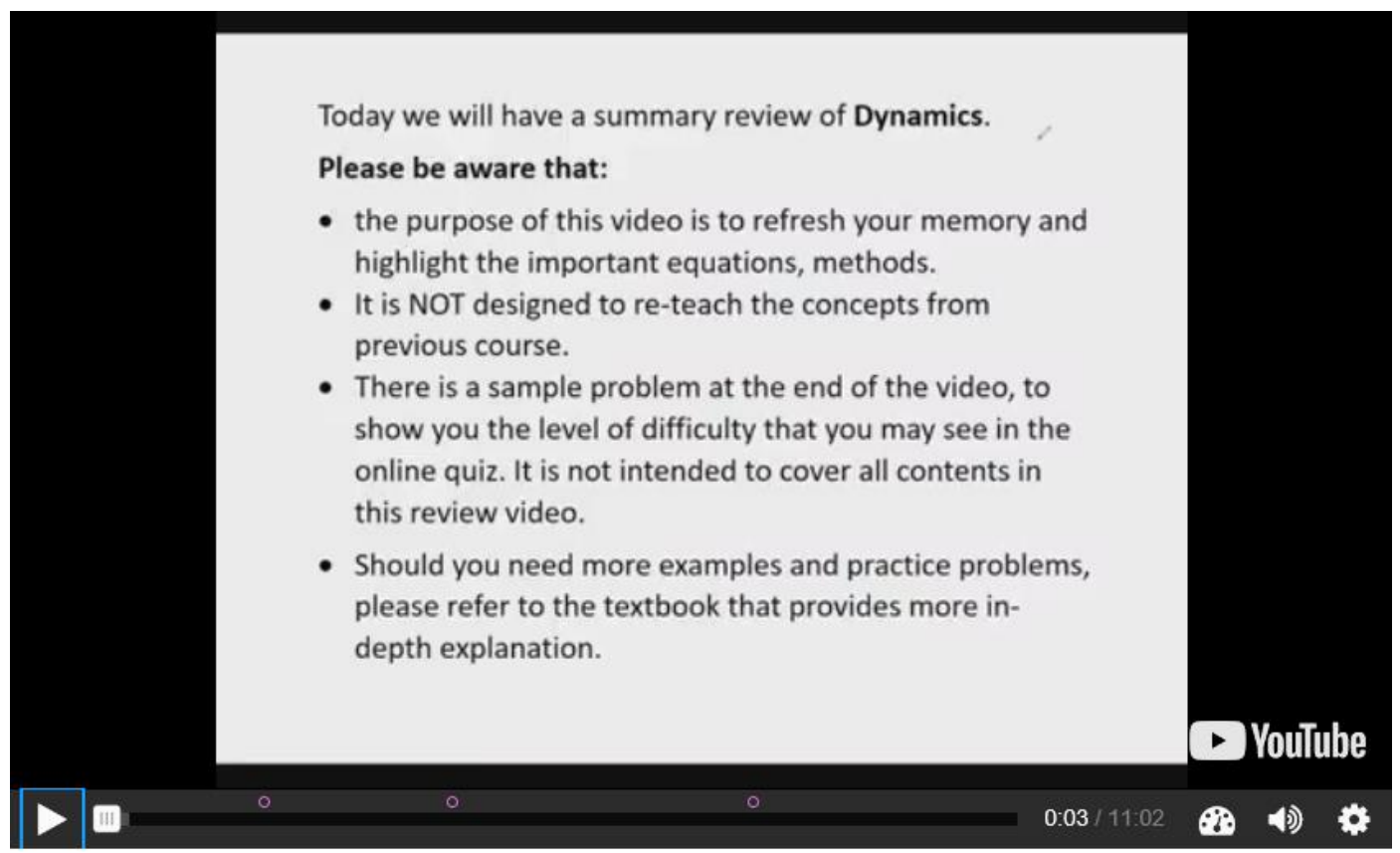

Figure 1. Clarifying the purpose of the review video at the beginning.

\section{2) Use the mouse to track content on the screen}

To keep each review video at a reasonable length, the instructor did not record the process of writing on the screen but scanned hand-written note sheets as images and used them as the slides. This method has saved video production time significantly: the instructor used one fifth of the time to produce each video compared to fall 2016 when the entire writing process was recorded on the screen. To compensate for the lack of cueing $[8,11]$ the viewer, the instructor used the mouse to point or highlight relevant information on the screen, as shown by the red dot in Figure 2. This feature helps direct the learner's attention, saving the viewer's cognitive resources that would have been spent on searching for information relevant to the voice explanation $[8,13]$. 
All videos were recorded in Zoom, a video conferencing tool that allows screen sharing and recording via a headset with mic. Zoom is free under the university license. It produces videos of decent quality. The videos can be exported to a common .mp4 format for additional editing if needed. Since our slides contain mostly equations, some text, and diagrams, we did not feel commercial quality video would benefit student learning to the degree to justify the cost, as found by an Educause Review study [12].

\section{3) Include interactive self-check questions}

In spring 2018, several conceptual questions were added to each online review videos to keep students engaged in the viewing process [8]. The questions were placed at time frames decided by the instructor, as shown by the purple dots on the timeline in Figure 2. When a question appears on the screen, the video would pause, and the viewer has to submit a correct answer in order to proceed. The instructor has designed the questions to serve two purposes: students can conduct a quick self-check; the questions can be used as bookmarks to help segmenting a longer video into smaller chunks [8]. Students can replay a segment if they couldn't figure out why they missed the question. Both the self-check questions and segmenting help students stay focused as the average amount of time viewers spend watching media is only about 4 minutes [12].

The interactive questions were simple multiple choice or True/False questions. They were created using H5P - a JavaScript-based, open source content collaboration tool. Students can check the correct answers of these questions but the answers are not recorded or collected.

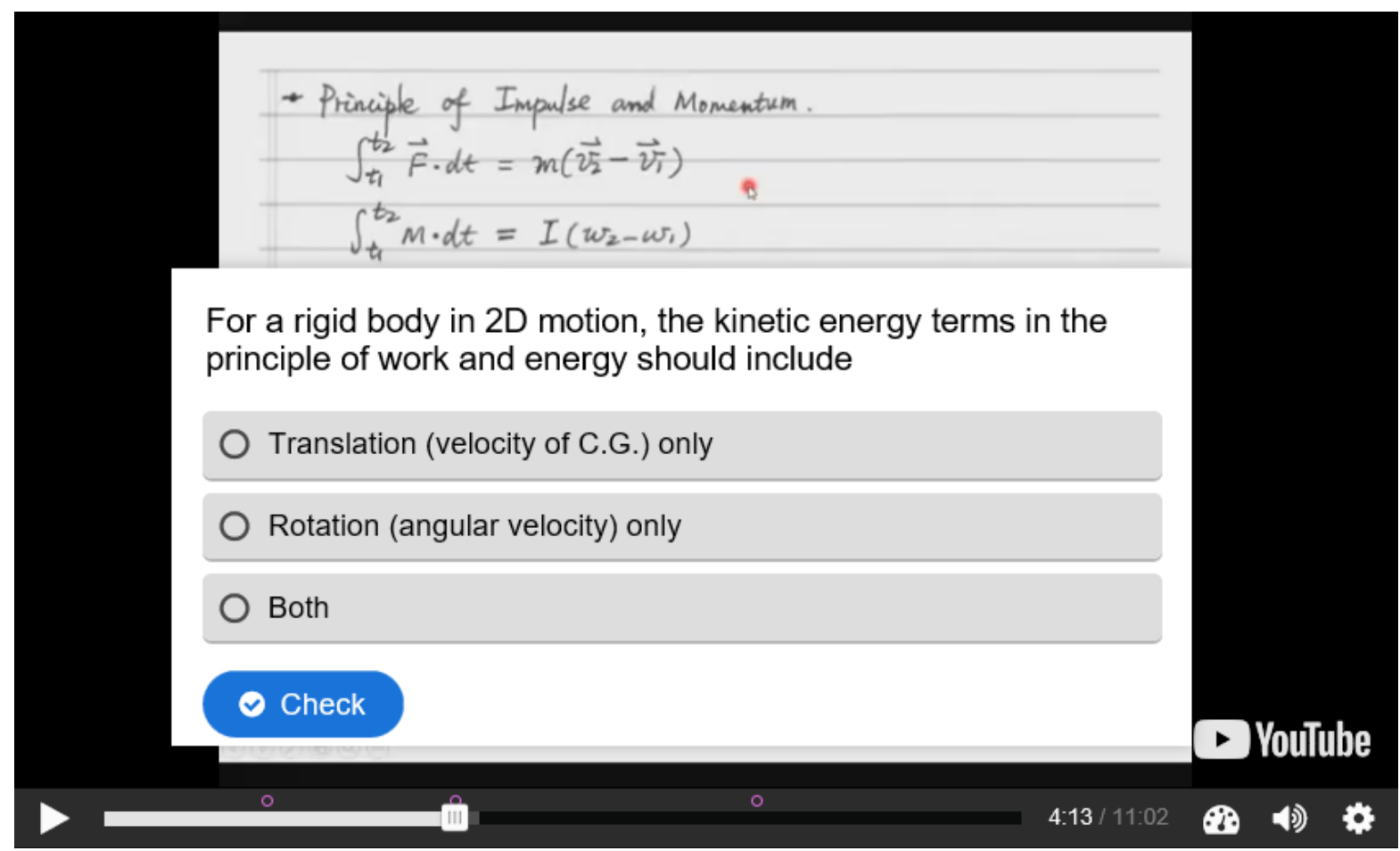

Figure 2. Sample screenshot showing the tracking cursor and self-check questions. 
4) Provide a sample problem to illustrate what is expected in the quiz

After the first video/quiz combo in spring 2018, students requested a sample problem to be added to the video so that they could adequately prepare for the online quiz. The request was answered immediately. Given that the quiz can take up to an hour (see details under $\mathrm{C}$ below) but the selfcheck questions in the video was meant to click-and-resume, it may be confusing for students to understand what is expected at the end of the review. Therefore, from the second review video and on, each video now includes a sample problem and solution to mirror the quiz, see Figure 3. However, to keep the video short, solution steps were not explained in detail.

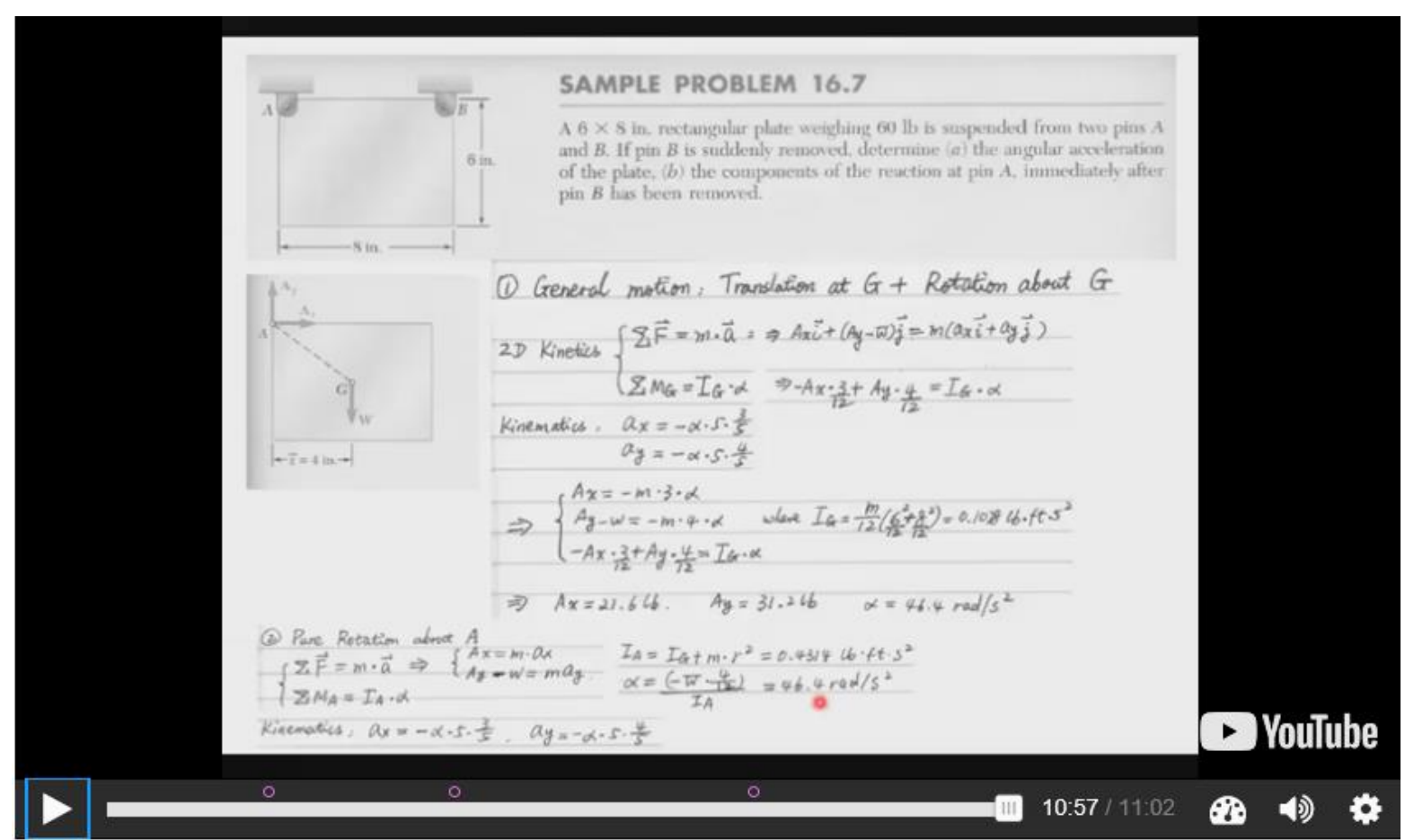

Figure 3. Example problem with solution at the end of the video.

All video slides except the opening slide and the sample problem in the review video are exported to a .pdf file and posted in the course site so that students have access to them to make their own notes, or to use them as a cheat sheet during the online quiz.

\section{Features of online quizzes}

Each online quiz is consisted of multiple algorithmic questions, all of them assess student ability to apply the concepts to engineering context as reviewed in the video. The algorithmic question feature in the learning management system allows each student to receive their own version of the question so they are tested on the same concepts but with different numbers.

For each quiz, students have between 40 to 60 minutes to complete the questions. Correct answers are revealed after each submission. Students can take a quiz up to two times, and the average score - rather than the higher one - is recorded by the gradebook. Back in 2016, the quiz used to keep the higher of the two scores, but the grading policy had to change when the instructor discovered that some students would skip all the problems in the first submission only 
to reach to the correct answers and then reverse engineered the solutions to submit them in the second attempt.

Per the content structure of the course, the first three videos (i.e. Statics, Dynamics, Strengths) and quizzes are concentrated in the first three weeks. In fact, video and quiz assignment 1 and 2 were two days apart within the first week. The third review assignment was assigned one week ahead of the due date. The fourth and fifth video/quizzes, as they are most relevant to the content later in the semester, are scheduled in the $10^{\text {th }}$ and $12^{\text {th }}$ week, therefore students will have an entire week to complete the review assignment.

\section{Student survey after each video/quiz review assignment}

On the same day a review video/quiz assignment is due, an anonymous survey regarding the "flipped review" approach is given to students at the end of the class. Students use the remainder of the class to answer the questions. The survey questions were custom-worded to match each review assignment. Typically, they contain rating, multiple select, and open-ended types of questions. Most of the questions used in fall 2016 were kept but revised for spring 2018. A question asking students to select the must-have features of an effective review video assignment was added, along with their perception on the ideal length of the video. A sample of survey questions can be found in Appendix A.

\section{Results}

In this section, we present assessments that directly and indirectly measure student learning. The direct learning assessment includes one informal, ungraded, quiz-like problem that students solved during class after they completed review 4 and 5 in each semester. The indirect learning assessment include student feedback from post-review assignment surveys and instructor observations. The responses analyzed and presented below came primarily from the 14 students enrolled in the spring 2018 class.

\section{A. Direct learning assessment}

In fall 2016 and spring 2018, students were evaluated on problem solving after the $4^{\text {th }}$ and $5^{\text {th }}$ review video/quiz were due. Both times, relevant physiological background was introduced in class first, then students were given a biomedical problem and 20 minutes to work on each problem. Students were told upfront that their performance on the problems would not be included in the course grade. No informal evaluation problems were given after review 1, 2, and 3 because all the biomedical problems available require at least 30 minutes which made in-class evaluation unfeasible.

A complete solution to each of the two problems requires four key skills. The number of students demonstrated such skills are summarized in Table 2. The majority of the students were able to transfer the skills into the unfamiliar biomedical context, exhibiting a higher level of comprehension. 
Table 2. Fall 2016 and spring 2017 responses to direct assessment.

\begin{tabular}{|l|l|l|l|l|}
\hline \multirow{2}{*}{ Skills required } & \multicolumn{2}{|l|}{ Success rate after Review 4 } & \multicolumn{2}{l|}{ Success rate after Review 5 } \\
\cline { 2 - 5 } & $\begin{array}{l}\text { 2016 Fall } \\
\text { 15 submissions }\end{array}$ & $\begin{array}{l}\text { 2018 Spring } \\
\text { 13 submissions }\end{array}$ & $\begin{array}{l}\text { 2016 Fall } \\
\text { 15 submissions }\end{array}$ & $\begin{array}{l}\text { 2018 Spring } \\
\text { 14 submissions }\end{array}$ \\
\hline Skill 1 & $14 / 15$ & $10 / 13$ & $14 / 15$ & $14 / 14$ \\
\hline Skill 2 & $13 / 15$ & $9 / 13$ & $14 / 15$ & $9 / 14$ \\
\hline Skill 3 & 0 & $3 / 13$ & $6 / 15$ & $7 / 14$ \\
\hline Skill 4 & $14 / 15$ & $3 / 13$ & $5 / 15$ & $7 / 14$ \\
\hline
\end{tabular}

\section{B. Indirect learning assessment}

\section{1) Quantative results}

Student surveys of review video/quizzes indicate student feel positive of both videos and quizzes, as shown in Table 3. The drop of mean values in Review 4 and Review 5 is suspected to be tied with the "school fatigue" because both review assignments were given close to the end of the spring semester and graduation. The same questions were asked in fall 2016. The responses then were also positive, despite slightly lower numeric values. We suspect that the differences in video features may offer an explanation. The 2016 version of the review videos did not have the H5P self-check questions or the example problem at the end of the video. We did include a few timestamps and used keywords to help viewers segmenting the topics in the videos.

Table 3. Overall means of spring 2018 responses on a 5-point scale from Strongly Agree (5) to Strongly Disagree (1).

\begin{tabular}{|l|l|l|l|l|l|}
\hline Common survey items & $\begin{array}{l}\text { Review 1 } \\
\mathbf{1 3} \text { responses }\end{array}$ & $\begin{array}{l}\text { Review 2 } \\
\mathbf{1 4} \text { responses }\end{array}$ & $\begin{array}{l}\text { Review 3 } \\
\mathbf{1 3} \text { responses }\end{array}$ & $\begin{array}{l}\text { Review 4 } \\
\mathbf{1 3} \text { responses }\end{array}$ & $\begin{array}{l}\text { Review 5 } \\
\mathbf{1 4} \text { responses }\end{array}$ \\
\hline $\begin{array}{l}\text { How many times did you } \\
\text { watch the XXX review video? }\end{array}$ & 1.15 & 1 & 1.23 & 1 & 1 \\
\hline $\begin{array}{l}\text { The XXX review VIDEO } \\
\text { helped me apply ME } \\
\text { concepts/skills to solve the } \\
\text { practice problem in class. }\end{array}$ & 3.77 & 3.64 & 3.92 & 3.62 & 3.36 \\
\hline $\begin{array}{l}\text { Rate the effectiveness of the } \\
\text { QUIZ in helping you solve } \\
\text { the practice problem in class. }\end{array}$ & 3.77 & 3.79 & 4.08 & 3.77 & 3.43 \\
\hline
\end{tabular}

\section{2) Quanlitative results}

Student selections of preferred features for an effective review video (Q5, Appendix 1) show that they would elect to include all of the features listed in the survey, with each feature had at least 7 votes from the class. Among them, three features rose to the top as must-have features (Q5.1, Appendix 1): \#2 Post the slides and handouts such as the equation sheet from the video in Canvas (named 12 times), followed by \#6 Provide an example problem in the video to illustrate 
what's expected in the online quiz (named 11 times), and \#7 Make sure viewers can pause and replay the video (named 11 times).

In answering the question regarding the ideal length of a review video (Q5.2, Appendix 1), 10 out of 13 students suggested the ideal length is about 10 minutes.

In answering the question of the preferred review format between online and in-class review, more than $62 \%$ of the class prefer online review. One student commented that "Online is MUCH better. It allows us to work at our own pace without holding the entire class back." Another stated "Definitely online review. I learn better when I have to figure out a problem on my own as opposed to listening to an instructor. The online video is a great tool that the students can use to best suite their ideal learning condition." A few students did prefer in-class review because "it is easier to focus and pay attention," and "(it) offered more opportunities for questions during inclass review." Some students feel they did not learn well from prerequisite courses, thus in-class review offers a better opportunity to relearn.

\section{3) End-of-semester survey}

At the end of the semester students were asked once more to rank the helpfulness of video/quiz for homework and project, etc. Measuring on the same 5-point scale as noted in Table 3, students responses rated the overall helpfulness of review videos 4 , and the overall helpfulness of the review quiz 3.64. More than $86 \%$ of the students agreed or strongly agreed that some types of review was necessary. $64 \%$ students prefer online review, similar to the results of each individual review.

\section{4) Instructor observation of course structure change}

The flipped review approach has made possible for class time to be used more meaningfully. Since no face-to-face lecture time was used to review fundamental ME concepts, 2-3 weeks of classes are saved across the semester, providing more time for students to learn at a higher cognitive level [14]. With the flipped review approach, the course can now include:

a. Three to four weeks (one additional week than prior) to cover at least one example problem per learning unit. Through these example problems, students have the opportunity to practice transferring knowledge from traditional engineering field to solving a biomedical problem.

b. One week designated to advanced/extended topics in biomechanics. This was never possible when the prerequisites were reviewed using class time.

In addition, by flipping the prerequisite review to outside of the class, the instructor feel students are more prepared in those reviewed contents than before, resulting in more in-depth discussion during the in-class time.

\section{Reflection and future direction}

Throughout the different phases of this project, we were not able to find previous studies under the search of "flipped review" or "flipped class" + "prerequisite review". We invite future studies, esp. senior level classes to try out the flipped review process and add to the flipped classroom literature.

We also recommend instructors who plan to adopt the flipped review approach build a learning outcome measurement that can be used consistently in the classroom-review and flipped-review classes so that the differences in learning would be more visible. In our project, ME 491 has 
evolved a lot over the past years. As a result, we do not have a consistent measure to see the differences in student learning outcome across different cohorts. The instructor did notice, however, with the flipped review approach, classroom teaching has been more pleasant. Students are more responsive to answer questions such as "where have we seen this before?" and "why do we need to know...?". Future studies should also be conducted in larger classes so that robust statistical analysis can be generated.

In terms of designing effective review assignments and integrating them to the course, we do have several tips to share with the engineering education community:

1. Distinguish between instructional videos and review videos and communicate the role of review videos in class. Student assumptions of course videos can lead to different expectations and affect how they utilize them. In a condensed conceptual review video, it is not realistic to include step-by-step solutions as the instructor works it out on the screen. Students should be made aware that their textbooks and class notes from previous courses are excellent resources if they need additional examples or practice problems. The quality of video production may not be as important as long as it is appropriate for the discipline and the types of information, nor is necessary to record the whole process of writing on the screen. This may not be the case for instructional videos in microbiology, however.

2. The purpose of the review assignments is to solidify the knowledge base so that new topics can build upon it. To achieve this goal, review videos must be bundled with graded work and mandated before a scheduled class. As one student wrote in a survey: "I feel like (the) video was significantly helpful; it just seems like there is too much stuff going on those first few weeks of the semester. I am glad the videos were mandatory, (be)cause I wouldn't have done it otherwise."

3. The types of questions asked in the post-review online quiz should assess students' application ability or higher according to Bloom's taxonomy of teaching, learning, and assessment [14]. This is different from instructional videos meant to teach a subject for the first time where simple recall questions may suffice. In contrast, review videos aim at pushing students to the higher order thinking skills such as analysis, synthesis, and creative problem solving. Simple questions asking students to list facts or identify among given choices will not be very valuable to achieving the goal.

4. We recommend review videos to include the must-have features as students elected. In addition to giving control of how they want the video to be played, students should have access to the handouts used by the review video so that they can take their own notes. An example problem should be included at the end of the video to explain to students what they are expected to understand upon a successful review.

\section{References}

[1] B. Honeycutt, "Ready to flip: three ways to hold students accountable for pre-class work," in Flipping the College Classroom: Practical Advice from Faculty, B. Honeycutt, Ed. Madison, Wisconsin: Magna Publications, 2016, pp. 13-15, 42-45. 
[2] G. S. Mason, T. R. Shuman and K. E. Cook, "Comparing the Effectiveness of an Inverted Classroom to a Traditional Classroom in an Upper-Division Engineering Course," IEEE

Transactions on Education, vol. 56, (4), pp. 430-435, 2013.

[3] J. Moffett, "Twelve tips for "flipping" the classroom," Medical Teacher, vol. 37, (4), pp. 331336, 2015.

[4] S. J. DeLozier and M. G. Rhodes, "Flipped Classrooms: a Review of Key Ideas and Recommendations for Practice," Educational Psychology Review, vol. 29, (1), pp. 141-151, 2017.

[5] L. C. Hodges, "Making Our Teaching Efficient: Flipping the Classroom," The National Teaching \& Learning Forum, vol. 24, (5), pp. 1-4, 2015.

[6] A. A. Hall and D. D. DuFrene, "Best Practices for Launching a Flipped Classroom," Business and Professional Communication Quarterly, vol. 79, (2), pp. 234-242, 2016.

[7]Velegol, S. B., \& Zappe, S. E., \& Brannon, M. L., Online Modules Enable Prerequisite Review and Mastery During Design Courses, presented at 2014 ASEE Annual Conference \& Exposition, Indianapolis, Indiana, June15-18, 2014. Available: https://peer.asee.org/22886

[8] C. J. Brame, "Effective Educational Videos: Principles and Guidelines for Maximizing Student Learning from Video Content," Cell Biology Education, vol. 15, (4), pp. es6-es6, 2016.

[9] Z, Woolfitt. (2015). The effective use of video in higher education. [Online]. Available: https://www.inholland.nl/media/10230/the-effective-use-of-video-in-higher-education-woolfittoctober-2015.pdf

[10] P. Guo, J. Kim and R. Rubin, "How video production affects student engagement: An empirical study of MOOC videos," presented at ACM Conference on Learning at Scale, Atlanta, GA, March 4-5, 2014.

[11] H. K. Tabbers, R. L. Martens and van Merriënboer, Jeroen J G, "Multimedia instructions and cognitive load theory: effects of modality and cueing," The British Journal of Educational Psychology, vol. 74, (Pt 1), pp. 71-81, 2004.

[12] M. Hibbert, What Makes an Online Instructional Video Compelling?, Columbia University Academic Commons, 2014, https://doi.org/10.7916/D8ST7NHP

[13] Q. Dunsworth and R. K. Atkinson, "Fostering multimedia learning of science: Exploring the role of an animated agent's image," Computers \& Education, vol. 49, (3), pp. 677, 2007.

[14] L. W. Anderson, D. R. Krathwohl and B. S. Bloom, A Taxonomy for Learning, Teaching, and Assessing: A Revision of Bloom's Taxonomy of Educational Objectives. (Abridg ed.) New York: Longman, 2001. 
[15] S. M. P. Schmidt and D. L. Ralph, "The Flipped Classroom: A Twist On

Teaching," Contemporary Issues in Education Research (CIER), vol. 9, (1), pp. 1, 2016. 


\section{Appendix A: Review Video Assignment Study Survey}

Q1. Check one: How many times did you watch the XXX review video?

$\begin{array}{llllll}1 & 2 & 3 & 4 & 5\end{array}$

Q2. Please check ALL that apply to your situation: After watching the video,

- I read more about the concepts.

- I went through another example.

- I went over more practice problems.

- I did nothing, although I perhaps should.

- I talked to other people (tutors, classmates, professor etc.) to get more help.

- I was able to keep up with this video and didn't need additional review.

- Other (write below):

Q3. Check one: The XXX Video helped me apply ME concepts/skills to solve the practice problem in class.

(Strongly agree) $5-4-3-2-1$ (Strongly disagree)

Q4. Check one: Please rate the effectiveness of the XXX Quiz as a tool to help you apply ME concepts/skills to solve the practice problem in class.

(Strongly agree) $5-4-3-2-1$ (Strongly disagree)

Q5. If you were to teach this class, what would you do to prepare an effective review video for your students? Circle all that apply.

1. Distinguish "review videos" from "teaching videos."

2. Post the slides and handouts such as the equation sheet from the video in Canvas.

3. Use the cursor to point on the screen to follow the narration in the video.

4. Include interactive questions in the video.

5. Use interactive questions as video bookmarks.

6. Provide an example problem in the video to illustrate what's expected in the online quiz.

7. Make sure viewers can pause and replay the video.

8. Make sure viewers can adjust screen size, volume, play speed, closed captioning, etc..

9. Provide more time for students to complete the review assignment.

10. Make the review assignment (Video + Quiz) mandatory.

11.Any others?

Q5.1. Which features above are the must-haves?

Q5.2. What's the ideal length of a review video?

Q5.3. Any additional features you would include?

Q6. Over the past several years, the course has been taught by two approaches: in-class review of prerequisites or online-review of prerequisites. If in-class review was conducted, 2 to 3 weeks of class time will be taken away from discussing the core of the course including advanced topics in contemporary biomechanics. If online-review was conducted (like Spring 2018), there will be more time for each topic to be discussed in depth. As a graduating senior of mechanical engineering, which approach do you prefer? Why? 
Q7. Open comments: Please write any suggestions on how to make a better review video, or how to integrate the video with the course in order to better prepare you for the upcoming classes.

Note: Q5, Q5.1, and Q5.2 were added to Review 3 survey and after. Q6 were added to Review 4 and 5. 